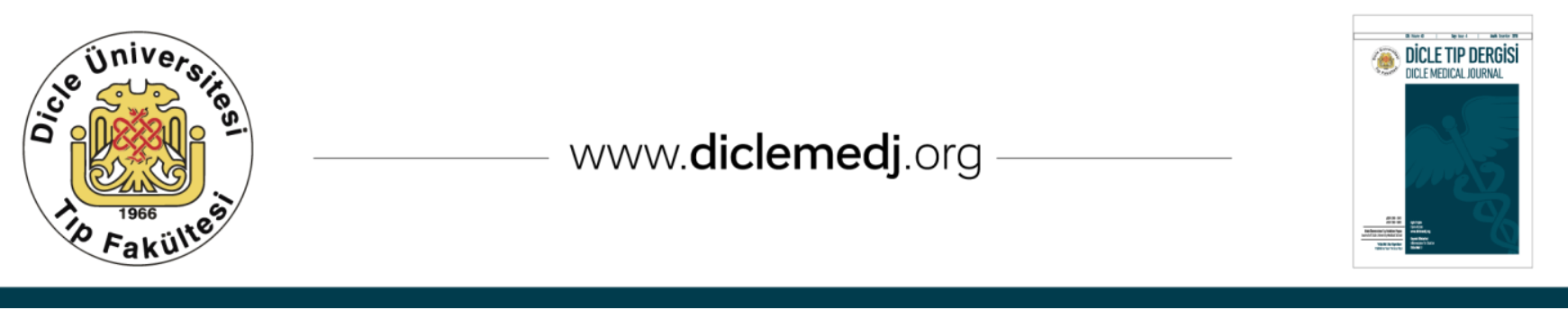

Özgün Araștırma / Original Article

\title{
Yoğun Bakım Ünitesinde Yatan Obstetrik ve Obstetrik Olmayan Hastaların Maliyet ve Sağkalım Analizlerinin Karşılaştırılması
}

\author{
Mehmet Erel ${ }^{1}$, Abdulmenap Güzel ${ }^{2}$, Feyzi Çelik³ ${ }^{3}$ Zeynep Baysal Yıldırım4, \\ Gönül Ölmez Kavak ${ }^{5}$
}

1 SBÜ Gazi Yaşargil Eğitim ve Araștırma Hastanesi, Anesteziyoloji ve Reanimasyon AD, Diyarbakır, Türkiye ORCID: 0000-0002-4416-8118

2 Dicle Üniversitesi Tıp Fakültesi, Anesteziyoloji ve Reanimasyon AD, Diyarbakır, Türkiye ORCID: 0000-0003-2261-0072

3 Dicle Üniversitesi Tıp Fakültesi, Anesteziyoloji ve Reanimasyon AD, Diyarbakır, Türkiye ORCID: 0000-0001-5986-8785

4 Dicle Üniversitesi Tıp Fakültesi, Anesteziyoloji ve Reanimasyon AD, Diyarbakır, Türkiye ORCID: 0000-0002-5264-1972

5 Dicle Üniversitesi Tıp Fakültesi, Anesteziyoloji ve Reanimasyon AD, Diyarbakır, Türkiye ORCID: 0000-0002-7745-7506

Geliş: 12.12.2018; Revizyon: 24.01.2019; Kabul Tarihi: 04.03.2019

Öz

Amaç: Gebeliğe bağlı gelişen komplikasyonlar yoğun bakım gerektiren önemli sağlık sorunlarıdır. Obstetrik hastaların gebeliğe bağlı spesifik hastalıklarının tanısı, tedavisi ve seçilmiş terapötik müdahaleleri non-obstetrik hastalardan daha farklıdır. Amacımız obstetrik ve non-obstetrik hastaların mortalite, morbidite ve maliyet analizlerini karşlaştırmaktır.

Yöntemler: Bu çalışma Yerel Klinik Araştırmalar Etik Kurulu onayı alındıktan sonra Anesteziyoloji ve Reanimasyon Kliniğinde yapılmıştır. Reanimasyon ünitesinde 01.01.2013 ile 31.12.2013 tarihleri arasında bir yıl boyunca faturalandırılan tüm hizmetler ve bu süre içindeki belgelenmiş olan tüm gelir ve giderler retrospektif olarak incelendi. Yoğun bakım ünitesinde yatan obstetrik ve non-obstetrik hastaların ortalama yaşı, tanısı, hastanede toplam yatış süreleri, mortalite ve maliyet analizleri detaylı olarak incelendi. Araştırmada, maliyet ve giderlerin akışını belirlemek için mali, idari ve tıbbi kayıtlardan yararlanıldı.

Bulgular: Yatırılan toplam 154 hastanın 31'i obstetrik, 123'ü non-obstetrikti. Obstetrik hastaların mortalite oranı nonobstetrik hastalara göre daha düşük saptandı ancak istatistiksel olarak anlamlı değildi $(p>0,05)$. Non-obstetrik hastalar ile kıyaslandığında obstetrik hastalar daha kısa yatış süresine ve daha düşük ortalama hasta başı maliyetlerine sahipti.

Sonuç: Maliyeti ne olursa olsun hala sosyal bir problem olan anne ölümlerini azaltmak için obstetrik hastaların hızlı değerlendirip hemen tedavi altına alınması gerektiği kanısındayız.

Anahtar kelimeler: Yoğun bakım ünitesi, gebelik komplikasyonları, maliyet analizi.

DOI: 10.5798/dicletip.539976

Yazışma Adresi / Correspondence: Abdulmenap Güzel, Dicle Üniversitesi Tıp Fakültesi, Anesteziyoloji ve Reanimasyon AD, Diyarbakır, Türkiye

e-mail:dr.amenap@gmail.com 


\title{
Cost and Survival Analysis of Obstetric and Non-Obstetric Patients Hospitalized in an Intensive Care Unit
}

\begin{abstract}
Objective: Complications due to pregnancy are important health issues that require intensive care. The diagnosis and treatment of, and selected therapeutic interventions for, gestational diseases for obstetric patients differ from those for non-obstetric patients. In this study, our aim was to compare mortality, morbidity and associated costs between obstetric and non-obstetric patients.

Method: This study was carried out at the Anesthesiology and Reanimation Department after approval of the Local Clinical Research Ethics Committee. Invoices for all reanimation services provided between January 1, 2013 and December 31, 2013, and all documented income and expenses during this period, were analyzed retrospectively. The mean age, diagnosis, total length of hospital stay, mortality and associated costs of the obstetric and non-obstetric patients in the intensive care unit were examined in detail by reference to financial, administrative and medical records.

Findings: Of the 154 patients hospitalized during the study period, 31 were obstetric and 123 were non-obstetric. The mortality rate of the obstetric patients was lower than that of the non-obstetric patients, but the difference was not significant $(\mathrm{p}>0.05)$. Compared with non-obstetric patients, obstetric patients had shorter hospital stays and lower average costs.

Conclusions: We believe that obstetric patients should be treated immediately, regardless of cost, to reduce maternal mortality, which remains a significant problem.
\end{abstract}

Keywords: Intensive care units, pregnancy complications, cost analysis.

\section{GíRiş}

Gebelik genellikle komplikasyonlar olmadan seyreden doğal bir olay olarak kabul edilirse de gebe kadınların yaklaşık \%0,1-0.9'unda yoğun bakım gerektiren ciddi sorunlar gelișebilmektedir ${ }^{1}$.

YBÜ'ye obstetrik hasta kabul oranları merkezden merkeze değişiklik gösterebilmektedir. Gebe hastaların YBÜ' lerine kabul sıklığı her 1000 doğumda $0.7-13.5$ olarak saptanmıştır ${ }^{2}$. Tüm çalışmalarda, obstetrik hastaların YBÜ kabulüne ilişkin en yaygın nedenler arasında obstetrik hemorajiler, gebeliğin hipertansif bozuklukları, sepsis, amniyotik sıvı embolisi ve tokolize bağlı pulmoner ödem gelmektedir. Yoğun bakım ünitesine kabul edilen obstetrik hastaların mortalitesi ise $\% 1,3-20$ arasinda değişmektedir ${ }^{3}$.

Sağlık hizmetinin sunumunda maliyetlerin belirlenmesi oldukça karmaşıktır. Bir hastalığın tedavi maliyeti her zaman aynı olmamakla birlikte o hastalığın tedavisinde kullanılan işçilik, araç-gereç ve hizmetler, kullanılan teknoloji, sağlık hizmetinin kalitesi, başta hekim olmak üzere istihdam edilen sağllk çalışanı ve diğer çalışanlar, hastanenin makineteçhizat durumu ve altyapısı da farklılık arz edebilir ${ }^{4,5}$. Yoğun bakım üniteleri en ciddi hastaların takip ve tedavisinin yapıldığ birimlerdir. Ayrıca hastaneler içinde kaynağın en fazla kullanıldığı, donanımı ve uygulamaları ile çok özel alanlardır. Yoğun bakımda bir hasta gününün maliyeti normal servislerdekinden yaklaşık üç-altı kat daha fazladır'6. Yoğun bakımda tedavi edilen hastaların maliyeti hakkında kesin bir rakam vermek oldukça zordur. Hastalığının şiddeti, çoklu organ yetmezliği, yaşı gibi faktörlere göre değișebilmektedir. Hastalara uygulanan girişimler ve bazı tedaviler artmış maliyet ve uzamış yatış riskini beraberinde getirebilmektedir7. 
Çalışmamızda obstetrik ile non-obstetrik hastalara ait maliyet analizini ve yoğun bakım mortalite oranlarını karşılaştırmayı amaçladık.

\section{YÖNTEMLER}

$\mathrm{Bu}$ çalışma Yerel Klinik Araştırmalar Etik Kurulu onayı (Tarih: 30.06.2014 Karar no: 30.06.2014/252) alındıktan sonra Anesteziyoloji ve Reanimasyon Kliniğinde yapilmıştır. Reanimasyon ünitesinde 01.01.2013 ile 31.12.2013 tarihleri arasında bir yıl boyunca faturalandırılan tüm hizmetler ve bu süre içindeki belgelenmiş olan tüm gelirler ve giderler retrospektif olarak incelenmiştir. Reanimasyon kliniği 1 yatak izole hasta odası olmak üzere 8 hasta yatağından oluşmaktadır. Her yatağın başında, bir adet mekanik ventilatör, bir adet monitör, birer adet merkezi aspiratör, oksijen ve kuru hava kaynağ bulunmaktadır. Birim net olarak $400 \mathrm{~m} 2$ ' lik bir alandan oluşmaktadır. YBÜ ekibinde, bir profesör, dönüşümlü olmak üzere üç araştırma görevlisi, biri sorumlu hemşire olmak üzere on beş hemşire ve on tane de çeşitli görevlerde olmak üzere hizmetli bulunmaktadır. Ayrıca; Reanimasyon Ünitesi, Dahiliye Yoğun Bakımı ve Genel Cerrahi Yoğun Bakımında görevli, vardiyalı çalışan üç güvenlik görevlisi bulunmaktadır.

Çalışmamızda, reanimasyon ünitesinde yatan obstetrik ve non-obstetrik hastaların yaşı, tanısı, hastanede toplam yatış süreleri, mortaliteleri ve maliyet analizleri detaylı olarak incelendi.

Araştırmamızda, maliyetlerin ve giderlerin akışını belirlemek için idari, mali ve tıbbi kayıtlardan yararlanılmıştır. Veriler; Maaş Tahakkuk Servisi, Döner Sermaye İşletme Müdürlüğü, Hastane Otomasyon Sistemi, Hastane Bilgi İşlem Merkezi, Taşınır Kontrol Servisi, SGK (Sosyal Güvenlik Kurumu) ve Hastane Teknik Servisinden temin edilmiștir.
Verilerin analizinde Geleneksel Maliyet Analizi yöntemi kullanılmıștır.

\section{Istatistik}

Verilerimizin istatistiksel değerlendirmesinde SPSS 21.0 paket programı kullanıldı. Ölçümsel değişkenler ortalama \pm standart sapma (SD) ile, kategorik değişkenler sayı ve yüzde (\%) ile gösterildi. Verilerin normal dağılıma uyup uymadığına bakıldı. Normal dağılım göstermeyen; iki seçenekli gruplamaların karşılaştırılmasında ise Mann Whitney U Testi uygulandı. Nitel değişkenlerin gruplar arası karşılaştırılması Chi-kare $(\chi 2)$ testi ile analiz edildi. İstatistiksel olarak $\mathrm{p}<0.05$ anlamlı sonuç olarak kabul edildi.

\section{BULGULAR}

\section{Demografik Veriler}

Yoğun bakım ünitemizde 2013 yılında yatırılan toplam 154 hastanın 31'i obstetrik, 123'ü nonobstetrik hastalardan oluşmaktaydı. Bu hastalara ait veriler Tablo I ve II de gösterilmiștir. Obstetrik ve non-obstetrik hastaların demografik verilerinin istatistiksel analizi karşılaştırıldığında; yaş ve mortalite oranları olarak aralarında bir ilișki saptanmamıștır. Yatış gün sayısına ve hastanın kaybedildiği güne göre ise aralarında ileri derecede anlamlı bir ilişki saptanmıștır ( $\mathrm{p} \leq$ 0.001) (Tablo III).

\section{Reanimasyon Kliniği Maliyet Analizi}

Reanimasyon gelirlerinin tümü fatura gelirlerinden elde edilmiştir. SGK' ya fatura edilen tutar 1.541.020,91 \$ olarak hesaplanmıștır. Giderler ise;

1) Direkt işçilik maliyeti: 1 öğretim görevlisi, 3 araştırma görevlisi, 15 hemşire ve 10 adet de geçici personel ücretleri olmak üzere toplamda 440.938,90 \$ olarak hesaplanmıștır. 
2) İşlem Giderleri: Reanimasyon kliniği 2013 yllına ait toplam işlem giderleri 493.327,89 \$'dir.

3) Diğer Yıllık Giderler: Genel giderler (yakıt, su, elektrik, temizlik, araç ve vergiler), bilişim giderleri, hasta ve personel yemek ücretleri (hasta ve personel eşit değerde ücretlendirilmiştir), güvenlik maliyeti ve SGK' ya gönderilen fatura tutarları üzerinden yapılan kesintilerden oluşmaktadır. Diğer yıllık giderlerin bir yıllık toplamı 196.750,00 \$ olarak hesaplanmıştır. Böylece bir yıllık toplam gider 1.131.016,80 \$ olarak tespit edilmiştir. 2013 yılına ait bir yılık net kar 410.004,11 \$ olarak hesaplandl.

Tablo I: Reanimasyon kliniğinde yatan hastaların tanıları.

\begin{tabular}{|c|c|c|c|}
\hline & Tanı & $\mathrm{n}(\%)$ & Toplam \\
\hline \multirow{6}{*}{ Obstetrik } & Postpartum kanama & $9(29)$ & \multirow{6}{*}{31} \\
\hline & Preeklampsi & $6(19,4)$ & \\
\hline & Plasenta Anomalileri & $6(19,4)$ & \\
\hline & Eklampsi & $5(16,1)$ & \\
\hline & HELLP & $4(12,9)$ & \\
\hline & Sepsis & $1(3,2)$ & \\
\hline \multirow{8}{*}{$\begin{array}{l}\text { Non- } \\
\text { obstetrik }\end{array}$} & $\begin{array}{l}\text { SolunumSistemi } \\
\text { Hastalıkları } \\
\end{array}$ & $51(41,4)$ & \multirow{8}{*}{123} \\
\hline & Multiple Travma & $44(35,8)$ & \\
\hline & Suisid & $7(5,7)$ & \\
\hline & Kafa Travması & $7(5,7)$ & \\
\hline & Kesici-DeliciAlet & & \\
\hline & $\begin{array}{l}\text { Yaralanması ve Ateşli } \\
\text { Silah Yaralanması }\end{array}$ & $6(4,9)$ & \\
\hline & Kardiyak Arrest & $5(4,1)$ & \\
\hline & Zehirlenmeler & $3(2,4)$ & \\
\hline
\end{tabular}

Tablo II: Reanimasyon kliniğinde yatan hastalara ait veriler.

\begin{tabular}{lccc}
\hline & Obstetrik & $\begin{array}{c}\text { Non- } \\
\text { obstetrik }\end{array}$ & Tüm Hastalar \\
\hline Cinsiyet (E / K) & $0 / 31$ & $72 / 51$ & $72 / 82$ \\
\hline Ortalama Yaş (Y1) & 31,6 & 38,5 & 37,1 \\
\hline $\begin{array}{l}\text { Hastanede Kalış } \\
\text { Süresi } \\
\text { (Toplam Gün) }\end{array}$ & 141 & 2890 & 3031 \\
\hline $\begin{array}{l}\text { Hastanede Kalış } \\
\text { Süresi } \\
\text { (Ortalama Gün) }\end{array}$ & 4,5 & 23,5 & 19,7 \\
\hline $\begin{array}{l}\text { Eksitus ( n) (\%) } \\
\text { Ortalama Kaçınc1 }\end{array}$ & $3(9,68)$ & $28(22,76)$ & $31(20,13)$ \\
$\begin{array}{l}\text { Günde } \\
\text { Eksitus Oldu? }\end{array}$ & 5 & 15,7 & 14,7 \\
\hline Eksitus yaş ortalamas1 & 35 & 40,3 & 39,8 \\
\hline
\end{tabular}

Tablo III: Reanimasyon kliniği obstetrik ve non-obstetrik hastalara ait veriler ve istatistiksel analizi.

\begin{tabular}{|c|c|c|c|c|}
\hline & $\begin{array}{c}\text { Obstetrik } \\
\text { Hastalar } \\
\text { mean } \pm \text { SD } \\
(\text { min - maks })\end{array}$ & $\begin{array}{c}\text { Non-obstetrik } \\
\text { hastalar } \\
\text { mean } \pm \text { SD } \\
\text { (min - maks) }\end{array}$ & $\mathrm{p}$ & \\
\hline Yaş & $\begin{array}{c}31,61 \pm 6,85 \\
(17-42) \\
\end{array}$ & $\begin{array}{c}38.54 \pm 20,52 \\
(4-89) \\
\end{array}$ & 0,309 & $\mathrm{p}>0,05$ \\
\hline $\begin{array}{l}\text { Yatış } \\
\text { Günü }\end{array}$ & $\begin{array}{c}4,55 \pm 3,39 \\
(1-18)\end{array}$ & $\begin{array}{c}23,74 \pm 43,06 \\
(1-330)\end{array}$ & 0,000 & $\mathrm{p} \leq 0.001$ \\
\hline $\begin{array}{l}\text { Eksitus } \\
\text { Günü }\end{array}$ & $\begin{array}{c}4,33 \pm 3.06 \\
(1-7)\end{array}$ & $\begin{array}{c}22,46 \pm 40,83 \\
(1-198) \\
\end{array}$ & 0,000 & $\mathrm{p} \leq 0.001$ \\
\hline
\end{tabular}

\section{Obstetrik Hastalar}

Obstetrik hastalara ait fatura tutarı gelirleri toplamda 91.481,95 \$, giderlerin toplamı ise $65.089,87$ \$ ve ortalama hasta başı maliyet 2100 \$ olarak tespit edildi. Obstetrik hastalara ait yıllık net kar 26.392,08 \$ olarak saptandı. Ayrıca obstetrik hastaların ortalama hasta başı günlük maliyeti 461,6 \$ ve ortalama hasta başı günlük karı 187,18 \$ olarak hesaplandı.

\section{Non-obstetrik Hastalar}

Non-obstetrik hastalara ait fatura tutarı gelirleri toplamda 1.449.538,96 \$'dir. Nonobstetrik hastalara ait toplam giderler 1.065.926,94 \$ ve ortalama hasta başı maliyeti 8666 \$ olarak hesaplandı. Non-obstetrik hastaların net karı 383.612,03 \$ olarak saptandl. Ayrica, non-obstetrik hastaların ortalama hasta başı günlük maliyeti 368,8 \$ ve ortalama hasta bașı günlük kârı 132,74 \$ olarak hesaplandi (Tablo IV).

Tablo IV: Obstetrik ve obstetrik olmayan hastaların gelir gider tablosu (2013).

\begin{tabular}{lcc}
\hline$\$$ & $\begin{array}{c}\text { Obstetrik } \\
\text { Hastalar }\end{array}$ & $\begin{array}{c}\text { Non-obstetrik } \\
\text { hastalar }\end{array}$ \\
\hline Toplam gelir & $91,481.95$ & $1.449 .538,97$ \\
\hline Toplam gider & $65.089,87$ & $1.065 .926,94$ \\
\hline Net kar & $26.392,08$ & $383.612,03$ \\
\hline Hasta başı ortalama kar & 187,18 & 132,74 \\
\hline
\end{tabular}

Çalışmamızdaki obstetrik ve non-obstetrik hastaların günlük maliyet analizi karşılaştırıldığında; İşlem geliri, işlem gideri, diğer giderler ve net kar açısından aralarında 
bir ilişki saptanmamıştır ( $\mathrm{p}>$ 0.05). Direkt İşçilik Maliyeti açısından obstetrik hastalar daha avantajlı tespit edildi ( $\mathrm{p} \leq 0.01$ ) (Tablo V).

Tablo V: Reanimasyon kliniği obstetrik ve non-obstetrik hastaların günlük maliyet analizi.

\begin{tabular}{lcccc}
\hline$\$$ & $\begin{array}{c}\text { Obstetrik } \\
\text { hastalar } \\
\text { mean } \pm \text { SD }\end{array}$ & $\begin{array}{c}\text { Non- } \\
\text { obstetrik } \\
\text { Hastalar } \\
\text { mean } \pm \text { SD }\end{array}$ & $\mathrm{p}$ & Sonuç \\
\hline İşlem geliri & $\begin{array}{c}1304,96 \pm \\
4673,68\end{array}$ & $\begin{array}{c}482,43 \pm \\
293,9\end{array}$ & 0,807 & $\mathrm{p}>0.05$ \\
\hline İşlem gideri & $\begin{array}{c}472,3 \pm \\
1509,64\end{array}$ & $\begin{array}{c}198,25 \pm \\
188,82\end{array}$ & 0,055 & $\mathrm{p}>0.05$ \\
\hline $\begin{array}{l}\text { Direkt } \\
\text { isççilik } \\
\text { maliyeti }\end{array}$ & $274,48 \pm 1,38$ & $144,36 \pm 1,21$ & 0,004 & $\mathrm{p} \leq 0.01$ \\
\hline $\begin{array}{l}\text { Diğer } \\
\text { giderler }\end{array}$ & $64.42 \pm 0,1$ & $64,42 \pm 0,1$ & 0,902 & $\mathrm{p}>0.05$ \\
\hline Net kar & $623,88 \pm$ & $\begin{array}{c}75,41 \pm \\
177,31\end{array}$ & 0,464 & $\mathrm{p}>0.05$ \\
\hline
\end{tabular}

Ancak iki grup yıllık maliyet analizi açısından karşılaştırıldığında; işlem geliri, direkt işçilik maliyeti ve diğer giderler açısından aralarında istatistiksel olarak anlamlı bir ilişki saptandı (p $\leq$ 0.001). Ayrıca işlem giderleri ve net kar olarak da aralarında önemli bir ilişki saptanmıştır ( $\mathrm{p} \leq$ 0.05) (Tablo VI).

Tablo VI: Reanimasyon kliniği obstetrik ve non-obstetrik hastalarının yıllık maliyet analizi.

\begin{tabular}{|lccc|}
\hline & $\begin{array}{c}\text { Obstetrik hastalar } \\
\text { mean } \pm \text { SD }\end{array}$ & $\begin{array}{c}\text { Non-obstetrik } \\
\text { Hastalar } \\
\text { mean } \pm \text { SD }\end{array}$ & $\mathrm{p}$ \\
\hline İşlem geliri & $2945,5 \pm 4714,46$ & $11959,25 \pm 22686,77$ & $\mathrm{p} \leq 0.001$ \\
İşlem gideri & $1140,7 \pm 157619$ & $3760,31 \pm 6638,62$ & $\mathrm{p} \leq 0.01$ \\
$\begin{array}{l}\text { Direkt işçilik } \\
\text { maliyeti }\end{array}$ & $660,31 \pm 492,96$ & $3447,1 \pm 6253,44$ & $\mathrm{p} \leq 0.001$ \\
$\begin{array}{l}\text { Diğer giderler } \\
\text { Net kar }\end{array}$ & $294,7 \pm 220,1$ & $1538,1 \pm 2790,47$ & $\mathrm{p} \leq 0.001$ \\
\hline
\end{tabular}

Reanimasyon ünitesinde 2013 yılı tüm hastaların korelasyon ilişkisinde; mortalite ile işlem giderleri, direk işçilik maliyeti ve diğer giderler arasında, $\mathrm{p} \leq 0.001$ ile pozitif yönde korelasyon saptandı. Buna göre mortalite arttıkça tüm giderler de artmaktadır. Tüm hastalardaki yatış gün sayısı ile işlem giderleri, direkt işçilik maliyeti ve diğer giderler arasında $\mathrm{p} \leq 0.001$ ile pozitif yönde korelasyon tespit edildi. Yatış gün sayısı arttıkça tüm giderler de artmaktadır. Tanı ile maliyet arasında da $\mathrm{p} \leq$ 0.001 ile anlamlı bir fark saptandı. Tanılara göre maliyet değişmektedir. Çalışmamızda mortalite ile tanı arasında ise anlamlı bir fark bulunmadı (Tablo VII).

Tablo VII: Mortalite ve yatış gün sayısının giderler ile arasındaki
korelasyon ilişkisi.
\begin{tabular}{|lcc|}
\hline & $\begin{array}{c}\text { Korelasyon } \\
\text { Katsayısı }(r)\end{array}$ & $p$ \\
\hline Mortalite-Işım Giderleri & 0,835 & $p \leq 0.001$ \\
Mortalite-D.İş̧ilik Maliyeti & 0,955 & $p \leq 0.001$ \\
Mortalite-Diğer Giderler & 0,955 & $p \leq 0.001$ \\
Yatış Gün Sayısı-Işslem Giderleri & 0,819 & $p \leq 0.001$ \\
Yatış Gün Sayısı-D.İşçilik Maliyeti & 0,967 & $p \leq 0.001$ \\
Yatış Gün Sayısı-Diğer Giderler & 0,967 & $p \leq 0.001$ \\
\hline
\end{tabular}

\section{TARTIŞMA}

Hastane hizmetleri yüksek maliyetli işlemlerdir ve hastanelerin de en maliyetli servisleri yoğun bakım hizmeti sunan servislerdir ${ }^{5,6,8,9}$.

Çalışmamızda obstetrik hastaların; yaş ortalamaları, hastanede yatış süreleri, morbidite-mortaliteleri daha düşük saptanırken, hasta başı ortalama günlük maliyetleri ve kâr oranları daha yüksek hastalar olarak tespit edilmiştir. Yıllık olarak karşılaştırıldığında ise işlem geliri, işlem gideri ve net kar non obstetrik hasta grubunda anlamlı derecede fazla görülmektedir. Ancak yoğun bakım hizmetlerinin kar amaçlı hizmet vermemesi gerektiği kanısındayız.

Reanimasyon ünitelerine hasta kabul edilme kriterleri merkezden merkeze değişmekle birlikte genelde hemodinamik bozukluk, solunumsal yetmezlik ve mental durum değişikliği nedeniyledir. Çalışmamızda obstetrik hasta grubunu postpartum kanamalar, gebeliğe bağlı hipertansif hastalar, plesenta anomalili ve HELP sendromlu hastalar oluşturmaktayken non-obstetrik hasta grubunu 
ise solunum yetmezlikli, multipl travmalı, kafa travmalı ve kardiak yetmezlikli hastalar oluşturmaktadır. Literatüre baktığımızda da benzer tanılı hastalar yoğun bakıma kabul edilmekte ancak hastalı derecesi veya ciddiyetleri farklılık arz edebilmektedir. $\mathrm{Bu}$ nedenlerin yanı sıra yoğun bakımdaki teknik alt yapı ve donanımdaki yetersizliklerden dolayı hastaların yatış gün sayısı, mortalite-morbidite ve maliyetleri farklılık gösterebilmektedir ${ }^{10}$.

Uysal ve ark. ${ }^{11}$ tarafından yapılan bir çalışmada, 1033 hasta değerlendirilmiş ve ortalama yaş 55 , geriatrik hasta ( $>65$ yaş) oranı \%38 olarak saptanmıştır. En sık yoğun bakım yatış endikasyonu solunum yetmezliği, hemodinamik dengesizlik ve mental durum değişikliği oluşturmuştur. Türker ve ark. ${ }^{12}$ tarafından yapılan bir çalışmada 1660 hasta retrospektif olarak incelenmiştir. Hastaların \%53,7 erkek, \%46,3 kadın olduğu ifade edilmiştir. Ortalama yaş erkeklerde 58,3, kadınlarda 57,1 olarak saptanmıştır. Hastaların en sık yatış endikasyonları; koroner arter hastalığı, solunumsal problemler, ilaç intoksikasyonları, stabil olmayan anjina pektoris, kardiyopulmoner arrest, böbrek hastalığı olarak tespit edilmiştir. Çalışmamızda; nonobstetrik hastaların tanı yüzdelerinde, solunum sistemi hastalıkları \%41,4 ile ilk sırada yer almaktadır.

Yoğun bakım ünitelerine kabül edilen hastaların önemli bir bölümünü obstetrik hastalar oluşturmaktadır. Hazelgrove13 ve arkadaşlarının İngiltere'de 14 farklı hastanenin YBÜ lerine kabul edilenlerin \%1,84'ünü (11385'in 210'u), tüm doğumların \%0,17'sini (122.850'nin 210'u) obstetrik hastalardan oluştuğunu bildirmişlerdir. Yoğun bakıma kabul nedenleri olarak en sık peripartum komplikasyonlar (gebeliğin hipertansif hastalı̆̆ $[\% 39,5]$ ve majör kanama [\%33,3]) olduğu bildirilmiştir. Demirkıran ve ark. ${ }^{14}$ çalışmasında yoğun bakımda takip ettikleri 125 obstetrik hastanın \%73,6'sını gebeliğe bağlı gelişen hipertansif hastalıklar (preeklampsi- eklampsi ve HELLP sendromu), \%11,2'sini obstetrik hemorajilerden oluştuğunu bildirmişlerdir. Panchal ve ark çalışmasında da YBÜ kabül edilen hastalar preeklamsi-eklampsi $(\% 36,6)$, postpartum hemoraji $(\% 28,3)$ ve plesental anomali-rüptür $\quad(\% 15,8)$ tanılı hastalarmış ${ }^{15}$. Çalışmamızdaki 15 hasta $(\% 48,4)$ gebeliğe bağlı hipertansif bozukluklardan dolayı reanimasyon ünitesinde takip edilmiştir.

Reanimasyon ünitesinde kalış süresi, daha önce bildirilen çalışmaların bazılarıyla benzerlik gösterirken bazılarından ise daha kısa veya daha uzun görülebilmektedir. Hastaların ihtiyaç duyduğu müdahalelerin sayısına ve türüne göre YBÜ'leri arasında önemli farklılıklar bulunmaktadır. Hazelgrove 'un çalışmasında da 7 obstetrik hasta daha ileri merkeze sevk edilmiş ve YBÜ' de kalan hastaların yaklaşık \%35,7'si 2 günden daha az süreyle YBÜ'de kaldığı saptanmıştır ${ }^{13}$. Uysal ve ark. ${ }^{11}$ ortalama YBÜ kalış süresi 4.3 gün, Ghorbani ve ark çalışmasında genel YBÜ kalış süresini $10,98 \pm 14,6$ gün olarak saptamışlar16. Literatürde obstetrik hastaların YBÜ kalış süresi non-obstetrik hastalar ile kıyaslandığında daha kısa olduğu bildirilmektedir. Yapılan bir derleme çalışmasında yoğun bakımda ortalama kalış süresini 1-6 gün olarak bildirmişlerdir ${ }^{17}$. Daha uzun süreli kalışın sebebi olarak şiddetli vakaların kabulüne atfedilmiştir.

Çalışmamızda non-obstetrik hastaların; hastanede yatış süreleri toplamda 2890 gün ve kişi başına ortalama 23,5 gündür. Obstetrik hasta grubunda hastanede yatış süreleri toplamda 141 gün ve hasta başına düşen gün sayısı ise ortalama 4,5 gündür. Çalışmamızda da görüldügü gibi obstetrik hastaların yatış süreleri daha kısa saptanmıştır.

Yoğun bakım ünitelerinde takip edilen hastalarin mortalite ve morbiditeleri değişkenlik gösterebilmektedir. Uysal ve ark. ${ }^{11}$ dahili YBÜ'de mortaliteyi \%43, Türker ve $\operatorname{ark}^{12}$ 
ise mortalite oranını \%21,4 olarak saptanmıştır. Goldhill ve ark. tarafından yapılan bir çalışmada ise İngiltere'de 24 adet yoğun bakımda tedavi edilen 12,162 hastanın verileri derlenmiş ve farklı yoğun bakımlar dikkate alındığında hastane mortalitesi \%24-41 arasında olduğu bildirilmiştir ${ }^{18}$. Zeeman'nın yaptığı derleme çalışmasında yaklaşık 30 çalışmayı incelemiş ve maternal mortalitenin (\%0-33) merkezlere göre farklılık gösterdiğini bildirmiştir ${ }^{17}$.

Çalışmamızda ise obstetrik hasta grubunda mortalite oranı $\% 9,68$, non obstetrik hasta grubunda ise \%22,76 olarak saptadık. Literatür ile karşılaştırdığımızda; Özellikle obstetrik hasta grubundaki mortalite oranları arasındaki farklılık yoğun bakım seviyesi ve hastaların yoğun bakıma kabul kriterlerinin farklılığından kaynaklanmaktadır. Non-obstetrik hasta grubu mortalite oranları daha yüksek saptanmıştır ve bunun nedeninin daha yaşlı grup, daha fazla yandaş hastalık ve multipl travma gibi faktörlerden kaynaklanmış olabileceğini düşünmekteyiz. Ayrıca Cardoso ve arkadaşlarının çalışmasında da belirtildiği gibi yoğun bakım gerektiren hastaların YBÜ'ne kabüldeki gecikmeler de mortaliteyi artıran faktörlerden biridir ${ }^{19}$.

Özellikle 3. basamak YBÜ'lerine kabul edilen bir hasta grubu da obstetrik hastalardır. Jacobs ve ark. $^{6}$ yoğun bakımda bir hasta gününün normal servislerdekinden ortalama 3-6 kat daha pahalıya mal olduğunu ve Amerika Birleşik Devletleri'nde tüm yatan hasta maliyetlerinin yaklaşık \%20'sinin yoğun bakım ünitelerinden kaynaklandığını bildirmişlerdir. Halpern ve ark. $^{9} 2000$ yılında ABD' de yaptıkları bir çalışmada, bir yıllık yoğun bakım maliyeti analizinde, toplam yoğun bakım maliyetini 55,5 milyar \$ olarak tespit etmişlerdir. $\mathrm{Bu}$ değerin, hastane masraflarının $\% 13,3$ ' ü, ulusal sağlık harcamalarının \%4,2'sini oluşturduğunu tespit etmişlerdir. Halpern ve arkadaşlarının yaptıkları başka bir çalışmada hasta başı ortalama günlük maliyeti
2010 verilerine göre 4300\$ olarak saptamışlardır ${ }^{20}$. Edbrooke ve ark. ${ }^{21}$ İngiltere' de 1996 ve 1997 yılları arasında yaptıkları çok merkezli bir çalışmada, yoğun bakım hastalarının, hasta başı günlük maliyetini 1406 $€$ olarak bulmuşlardır. Bu çalışmalara benzer bir çalışmada da, Sznajder ve ark. ${ }^{22}$ tarafından yapılmıştır. 1996 yılında Paris' te 7 yoğun bakım ünitesinde 3 ay boyunca toplam 211 yoğun bakım hastası üzerinde yaptıkları bir çalışmada, hasta başı ortalama maliyeti 14130 \$ olarak bulmuşlardır.

Çalışmamızda, non-obstetrik hastaların ortalama hasta başı günlük maliyeti 368,8 \$ ve ortalama hasta başı maliyeti $8666 \$$ olarak hesaplandı. Ayrıca hasta başı ortalama günlük kâr 132,74 \$ olarak hesaplandı. Literatür ile karşılaştırdığımızda özellikle gelişmiş ülkelerde yoğun bakım ünitelerinde günlük hasta başı ve hasta başı ortalama maliyeti daha yüksek görülmektedir.

Mc Cord ve ark. ${ }^{23} 1995$ yılında Bangladeş' te bir obstetrik yoğun bakımında, obstetrik hastalar üzerinde yaptıkları bir çalışmada, hasta başı günlük maliyeti 13,15 \$ olarak tespit edilmiștir. Richard ve ark. ${ }^{24}$ tarafindan Afrika' daki bir obsbtetrik yoğun bakımında yapılan bir çalışmada, 2003-2005 yılları arasında izlenen obstetrik hastaların ortalama hasta bașı yıllık maliyeti 136 \$ olarak saptanmıştır. Orsini ve ark. $^{25}$ 2009-2012 yılları arasında, New York' da yaptıkları prospektif bir çalışmada, obstetrik hastaları incelemişler. Hastaların 19'u obstetrik yoğun bakıma ihtiyaç duymuştur. Bu hastaların ortalama yoğun bakım maliyeti 9288 \$ ve toplam yoğun bakım maliyeti ise 210578 \$ olarak tespit edimiştir. Heinonen ve arkadaşlarının yaptıkları çalışmada obstetrik hastaların ortalama hasta başı maliyeti 5000 \$ olarak saptamışlardır²6.

Çalışmamızda ise, obstetrik hastaların ortalama hasta başı günlük maliyeti 461,6 $\$$ ve ortalama maliyeti 2100 \$ olarak saptadık. Ayrıca hasta 
başı ortalama günlük kâr 187,18 \$ olarak tespit edildi.

Obstetrik hastaların sağlık problemleri akut gelişen olaylar oldukları için, hasta tanıları arasında kronik seyirli hastalıklar ve multitravma da bulunan non-obstetrik hastalara oranla daha düşük maliyete sahiptir. Yoğun bakımda yatan hastalara, hastalığın şiddetine ve türüne göre değişen derecelerde invaziv işlemler ve yoğun bakım hizmetleri uygulanmaktadır. Tüm bu işlem ve hizmetler, genellikle ilk birkaç gün içinde yoğunlaşmaktadır. Bu yüzden, hastalarda erken günlerde eksitus gelişmişse maliyet daha yüksek, geç günlerde eksitus gelişmişse maliyet daha düşük saptanmıştır.

Yatış süresi uzadıkça, hastalarda yoğun bakımda infeksiyöz komplikasyonların gelişme riski de artmaktadır. Bu iki durumun bir uzamış yatış-artmış maliyet kısır döngüsüne sebep olabilmektedir? ${ }^{7}$.

Özellikle yoğun bakım hizmetlerinde maliyeti etkileyen en önemli parametrelerinden birisi direkt ișçiliktir. Esatoğlu ve ark.4 hastane giderlerinin ortalama \%22,33'ünü direkt ilk madde ve malzeme giderleri, \%52,84'ünü direkt işçilik giderleri ve \%24,83'ünü de genel üretim giderleri olduğunu tespit etmişlerdir. Shelley ve ark. ${ }^{27}$ tarafından yapılan çalışmada hastane giderlerinin yaklaşık \%53'ünün direkt tıbbi giderlerden oluştuğunu ifade etmişlerdir.

Çalışmamızda, non-obstetrik hastaların işlem giderleri \%43, direkt işçilik giderleri \%39, diğer giderler ise \%18 olarak tespit edildi. Obstetrik hastaların işlem giderleri \%54, direkt işçilik giderleri \%32, diğer giderler ise \%14 olarak saptadık. Çalışmamızdaki sonuçlar literatür ile uyumlu görünmekte ve personel giderleri önemli bir gider olarak yer teşkil etmektedir.

Necdet ve ark. ${ }^{28}$ tarafından yapılan çalışmasında travmatik beyin hasarının yoğun bakım maliyetlerini artırdığını ve ayrıca yüksek düzeyde mortalite oranına da sahip olduğunu bildirmişlerdir. İntrakraniyal kanama ile başvuran YBÜ hastaları yüksek mortalite ve maliyete sahiptirler. $\mathrm{Bu}$ çalışmada elde edilen başka bir sonuç ise mortalite ile maliyet ve mortalite ile direk işçilik arasında pozitif bir korelasyondur. Tanı ile maliyet arasında da istatistiksel olarak anlamlı ilişki saptamışlardır ${ }^{29}$.

Çalışmamızda, tüm hastaların mortalite ve işlem giderleri, mortalite ve direk işçilik maliyeti, mortalite ve diğer giderler arasında, $\mathrm{p} \leq 0.001$ ile pozitif yönde korelasyon saptandı. Mortalite arttıkça tüm giderler de artmaktadır.

Çalışmamızda yatış gün sayısı ile maliyetler arasında pozitif bir korelasyon mevcuttu. Tanı ile maliyet arasında $\mathrm{p} \leq 0.001$ ile anlamlı farklılık bulunmaktadır. Tanılara göre maliyet değişmektedir.

\section{SONUÇ}

Yoğun bakım hizmetleri oldukça maliyetli ve personel giderleri önemli bir kalem olarak göze çarpmaktadır. Obstetrik hastalar non-obstetrik hastalara kıyasla, tedaviye daha iyi cevap verebilmekte, daha kısa yatış süreleri ve daha düşük morbidite-mortalite oranlarına sahiplerdir. Hasta başı ortalama günlük maliyetleri ise daha yüksek iken yıllık bazda maliyetleri daha az hastalardır.

Son söz olarak anne ölümlerini azaltmak için obstetrik hastaların hızlı değerlendirilip hemen tedavi altına alınması ve yoğun bakım tedavisi gerekli görüldüğünde ise ivedilikle yoğun bakım ünitelerine transfer edilmesi gerektiği kanaatindeyiz.

$\mathrm{Bu}$ çalışma 21. Uluslararası Yoğun Bakım Sempozyumunda poster olarak sunulmuştur.

Çıkar Çatışması Beyanı: Yazarlar çıkar çatışması olmadığını bildirmişlerdir.

Finansal Destek: Bu çalışma her hangi bir fon tarafından desteklenmemiştir. 
Declaration of ConflictingInterests: The authors declare that they have no conflict of interest.

Financial Disclosure: No financial support was received.

\section{KAYNAKLAR}

1. Wheatley E, Farkas A, Watson D. Obstetric admissions to an intensive therapy unit. Int J Obstetr Anaesth 1996; 5: 221-4.

2. Pollock W, Rose L, Dennis CL. Pregnant and postpartum admissions to the intensive care unit: a systematic review. Intensive Care Med. 2010; 36: 1465-74.

3. Chantry AA, Deneux-Tharaux C, Bonnet MP, BouvierColle MH. Pregnancy related ICU admissions in France: trends in rate and severity, 2006-2009. Crit Care Med 2015; 43: 78-86.

4. Esatoğlu AE, Ağırbaş İ, Payziner PD. ve ark. Ankara Üniversitesi Tıp Fakültesi Hastaneleri'nde Maliyet Analizi. Ankara Üniversitesi Tıp Fakültesi Mecmuası. 2010; 63: 17-27.

5. Zengin S, Al B, Yavuz E, et al. Analysis of complaints lodged by patients attending a university hospital: a 4year analysis. J Forensic Leg Med. 2014 Feb; 22: 121-4.

6. Jacobs P, Noseworthy TW. National estimates of intensive care utilization and cost: Canada and United States. Crit Care Med. 1990; 18: 1282-6.

7. Eren O.Ö., Kalyoncu U., Andıç N., Şardan Y.Ç., Yoğun bakım ünitesinde hasta maliyetini etkileyen faktörler. Selçuk Tip Derg 2009; 25: 195-202.

8. Karasioğlu F, Çam AV. Sağllk İşletmelerinde Maliyet Analizi: Karaman Devlet Hastanesinde Birim Muayene Maliyetlerinin Hesaplanması. Niğde Üniversitesi İIBF Dergisi. 2008; 1: 15-24.

9. Halpern NA, Pastores SM, Greenstein RJ. Critical care medicine in the United States 1985-2000: An analysis of bed numbers, use and costs. Critical Care Medicine 2004; 32: 1254-9.

10. Gaffney A.Critical care in pregnancy--is it different? Semin Perinatol. 2014 Oct; 38: 329-40.

11. Uysal N, Gündoğdu N., Börekçi Ş, Dikensoy Ö. Prognosis of Patients in a Medical Intensive Care Unit of a Tertiary Care Centre, Yoğun Bakım Derg 2010; 1: 1-5.
12. Türker İ, Gürsoy H, Özyılkan E, Dönderici Ö. Dahiliye yoğun bakım ünitesine yatan hastaların yatış nedenlerinin ve sürelerinin incelenmesi. İç Hastalıkları Dergisi 2008; 15: 2-102.

13. Hazelgrove JF, Price C, Pappachan VJ, Smith GB. Multicenter study of obstetric admissions to 14 intenisve care units in southern England. Crit Care Med 2001; 29: 770-5.

14. Demirkıran O, Dikmen Y, Utku T, Urkmez S. Critically ill obstetric patients in the intensive care unit. Int J Obstet Anesthesia 2003; 12: 266-70.

15. Panchal S, Arria AM, Harris AP. Intensive care utilization during hospital admission for delivery: prevalence, risk factors, and outcomes in a statewide population. Anesthesiology. 2000 Jun; 92: 1537-44.

16. Ghorbani M, Ghaem H, Rezaianzadeh A, et all. A study on the efficacy of APACHE-IV for predicting mortality and length of stay in an intensive care unit in Iran. F1000Res. 2017 Nov 20; 6: 2032. doi: 10.12688/f1000research.12290.1. e Collection 2017.

17. Zeeman GG. Obstetric critical care: a blueprint for improved outcomes. Crit Care Med. 2006 Sep; 34 (9 Suppl): 208-14.

18. Goldhill DR, Sumner A. Outcome of intensive care patients in a group of British intensive care units. Crit Care Med. 1998; 26: 1337-45.

19. Cardoso LT, Grion CM, Matsuo T, et all. Impact of delayed admission to intensive care units on mortality of critically ill patients: a cohort study. Crit Care. 2011; 15: R28. doi: 10.1186/cc9975. Epub 2011 Jan 18.

20. Halpern NA, Goldman DA, Tan KS, Pastores SM. Trends in Critical Care Beds and Use Among Population Groups and Medicare and Medicaid Beneficiaries in the United States: 2000-2010. Crit Care Med. 2016 Aug; 44: 1490-9.

21. Edbrooke DL, Ridley SA, Hibbert CL, Corcoran M: Variations in expenditure between adult general intensive care units in the UK. Anaesthesia. 2001, 56: 208-16.

22. Sznajder M, Aegerter P, Launois Ret all A costeffectiveness analysis of stays in intensive care units. Intensive Care Medicine. 2001; 27: 146-53.

23. Mc Cord C, Chowdhury Q. what it can mean for emergency obstetric care, International Journal of Gynecology \& Obstetrics. 2003; 81: 83-92.

24. Richard F, Ouédraogo C, Compaoré J, Dubourg D. Reducing financial barriers to emergency obstetric care, Tropical Medicine \& International Health. 2007; 12: 972-81. 
25. Orsini J, Butala A, Diaz L, et all. Clinical Profile of Obstetric Patients Admitted to the Medical-Surgical Intensive Care Unit (MSICU) of an Inner-City Hospital in New York, J Clin Med Res. 2012; 4: 314-17.

26. Heinonen S, Tyrvainen E, Saarikoski S, Ruokonen E. Need for maternal critical care in obstetrics: A population-based analysis. Int J Obstet Anesthesia. 2002; 11: 260-4.

27. Shelley M. The Staggering Cost of Illness and İnjury. Canadian Medical Association. 2003; 168: 332-5.
28. Süt N, Dilek M, Travmatik beyin hasarının yoğun bakım maliyeti ve sağ kalım analizleri. Ulus Travma Acil Cerrahi Derg. 2010; 16: 149-54.

29. Fernando SM, Reardon PM, Dowlatshahi D, et all. Outcomes and Costs of Patients Admitted to the ICU Due to Spontaneous Intracranial Hemorrhage. Crit Care Med. 2018 May; 46: 395-403. 